\title{
RESEARCHES ON DOUBLE CURTAIN WALL BREAKWATER
}

\author{
Shigeru Tanaka \\ Professor of Hydraulics \\ Department of Civil Engineering \\ Kobe University, Kobe, Japan
}

\section{INTRODUCTION}

It has been clarified by some researchers(R. L. Wiegel ${ }^{1)}$, F. Urse $11^{23}$, R. Morihira \& S. Anezaki ${ }^{3}$, etc.) that the singie curtain wall breakwater has no good wave-dissipating effect at the usual coastal area where the ratio of water-depth to wave-length is considerably small. The author has made researches concerning "Multiple Curtain Wall Breakwater", anticipating the supposition that it may be very effective for the dissipation of wave energy even at a shallow coastal zone, because of its peculiar effectiveness upon wave dissipation.

Double curtain wall breakwater is composed of two parallel rows of curtain walls attached to the supporting props installed at an adequate interval. The interval of the said two rows is very important, and the determination of a proper interval, relating to a high wind wave having a definite length and a definite wave height, is one of the main objects of this research.

These researches were mainly made experimentally. At first the author assumed that the design wave had the period of $5-6$ sec, the length of $50-60 \mathrm{~m}$ and the height of $1.5 \mathrm{~m}$. The results of the model experiment show that the double curtain wall breakwater, installed at the depth ranging 3 $10 \mathrm{~m}$, has remarkable effect on wave dissipation. Secondly the author selected a particular location on the north coast of Osaka Bay where the design wave has the period of $7-9$ sec, the wave length of $65-70 \mathrm{~m}$ and the wave height of 3.8 $-4.0 \mathrm{~m}$ at offshore. At the expected site of thebreakwater, the sea bottom is flat and nearly horizontal, and the water depth under the condition of the extraordinary high tide is $10.5 \mathrm{~m}$ above the sea bottom, and an experiment was carried out by the model for this location.

One kind of model was constructed in a shallow basin of $0.5 \mathrm{~m} \times 25 \mathrm{~m} \times 30 \mathrm{~m}$, in the scale of 1 to 40 and of 1 to 70 , in order to determine its transmission coefficient of wave height. Another kind of model was made in a glazed steel frame tank of $1.6 \mathrm{~m} \times 1.8 \mathrm{~m} \times 28 \mathrm{~m}$, equipped with a piston type wave generator operated by $5 \mathrm{HP}$ motor. The scale of this model is 1 to 10 , and its purpose is to secure the surface disturbance and to trace the trajectories of small suspended particles by a $16 \mathrm{~mm}$ cine camera and a high speed motion camera. 


\section{WAVE DISSIPATION MECHANISM}

The schematical section of the breakwater studied by the author is shown in Fig. 1. The crown of the front wall is placed somewhat lower than the still water level. When an incident wave collides the front wall, it trips over it and jumps into the zone between the two curtain walls. A part of the energy of incident wave is transmitted into the inserted zone through the opening under the front curtain wall. Also, a part of the energy is dissipated by the collision of incident wave against the surface of the front wall. As far as the apparent conditions on the front surface of the front wall and the lower opening under the wall are concerned, they are the same as those of the usual single curtain wall breakwater. But, in the case of the double curtain wall breakwater, the incident wave from the offshore breaks when it collides with the front wall and spills into the inserted zone, so that the orbit of water particle in wave motion is disturbed remarkably. Under such circumstances, the peculiar oscillation of water surface, the characteristics of which differ from those of offshore wave, takes place inside the space between the two walls, and this newly generated special movement of water mass restricts the passing of wave energy through the opening under the front wall.

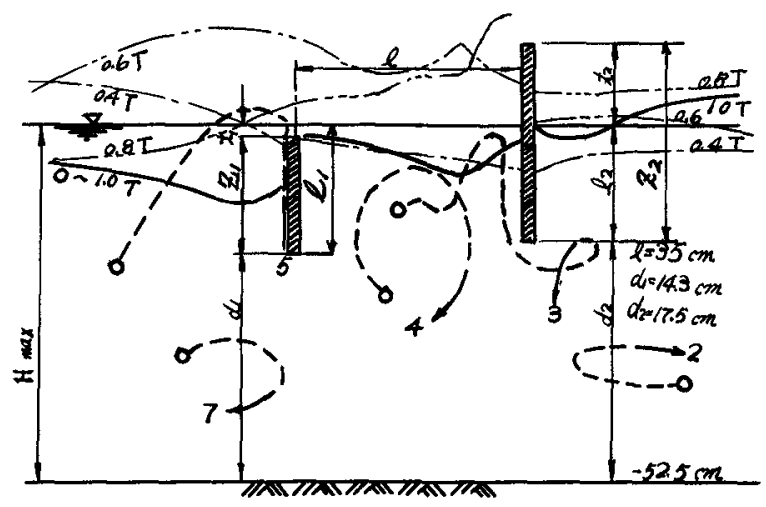

Fig. 1. Water surface undulation and particle trajectories in the case of small interval, 1 between walls.

Fig. 1 and Fig. 2 show the results obtained by model experiments, representing the undulating figures of the water surface and also show the trajectories of small particles suspended in water. 


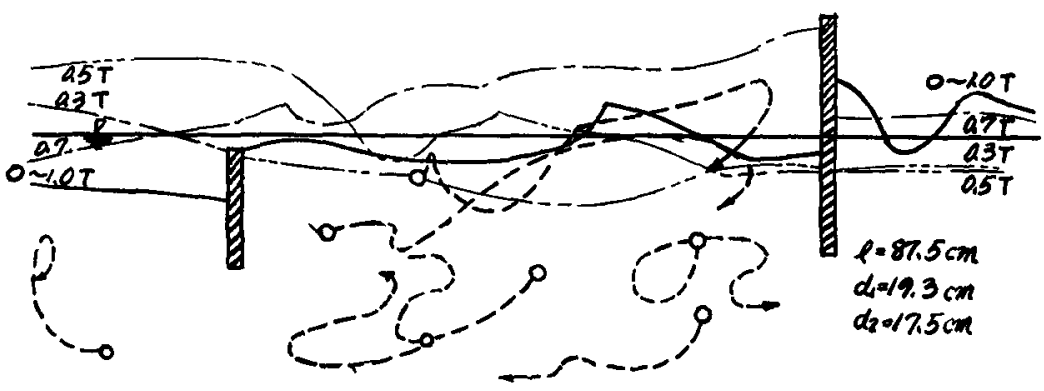

$-225 \mathrm{~cm}$

Fig. 2. Water surface undulation and particle trajectories in the case of an appropriate interval, 1.

These figures were obtained by analizing the pictures by $16 \mathrm{~mm}$ cine-films and high-speed-films which took the motion of water surface and of small suspended particles through a side glass plate of the said wave tank where large-scale experiments were made. In these experiments many absorbent cotton pleces of $5-6 \mathrm{~mm}$ in size, previously immersed in coloured benzıne, were used as the said suspended particles. Water surface undulation and particle trajectories shown in Fig. I and Fig. 2, have a close interrelationship. As far as the latter are concerned, those in Fig. I show ellipse-like orbits which are not so deformed from those in F1g. 2 show peculiar stretched lines which are not alike the elipse-like ones. In the case of large interval, l, particle trajectories again approaches ellipse-like ones. Fig. 3 shows another results obtained by the author, showing water surface undulation and particle trajectories.

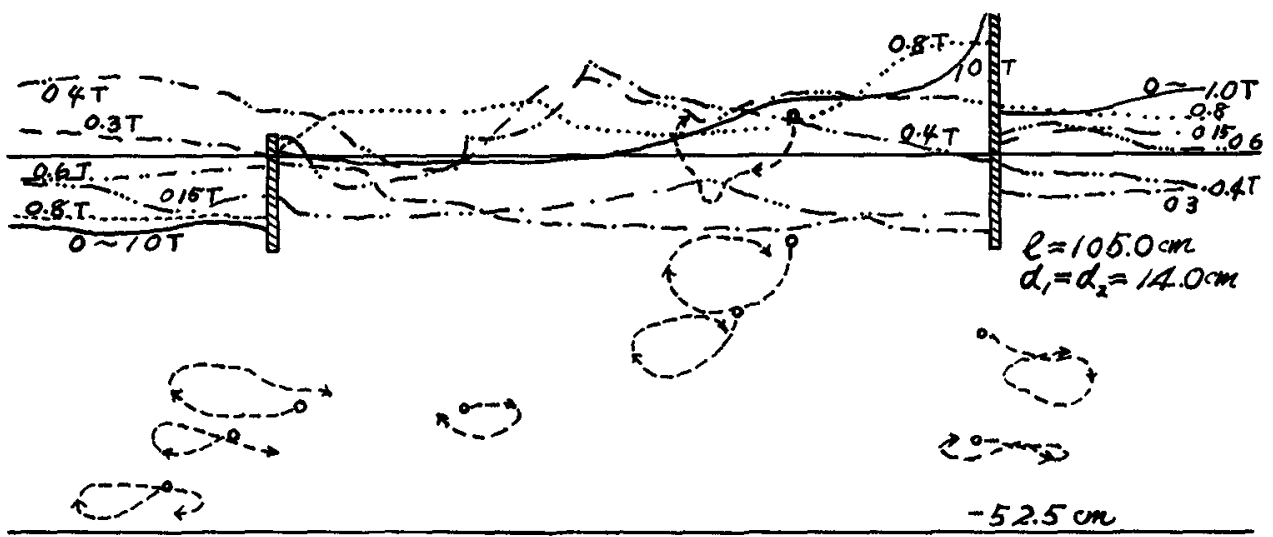

Fig. 3. Water surface undulation and particle trajectories in the case of large interval, 1 , between walls. 
When the transmission coefficient of wave height, $H_{T} / H_{I}$ (the ratio of the transmitted wave-height to the incident wave-height), is comparatively small, it is clear that the suspended particles do not form the usual ellipse-like orbits, as those particles do in shallow water having wind wave, but they show peculiar stretched ones. On the other hand, when the above-stated ratio is comparatively large, the majority of the particle trajectories is nearly the same as those in shallow water having wind waves.

\section{WAVE HEIGHT TRANSMISSION COEFFICIENT}

\section{(1) Case 1}

The model was constructed in a shallow pool, in the scale of 1 to 40 , based on a precise contour lines given from a precise map. The model of the double curtain wall breakwater was installed at the position of water depth ranging from 3 $\mathrm{m}$ to $10 \mathrm{~m}$, in such a manner as shown in Fig. 4. The design wave characteristics are the same as previously stated, and the tidal range at the site is $1.8 \mathrm{~m}$. The experiments were performed at $L$. W. L. and $H$. W. L., respectively.

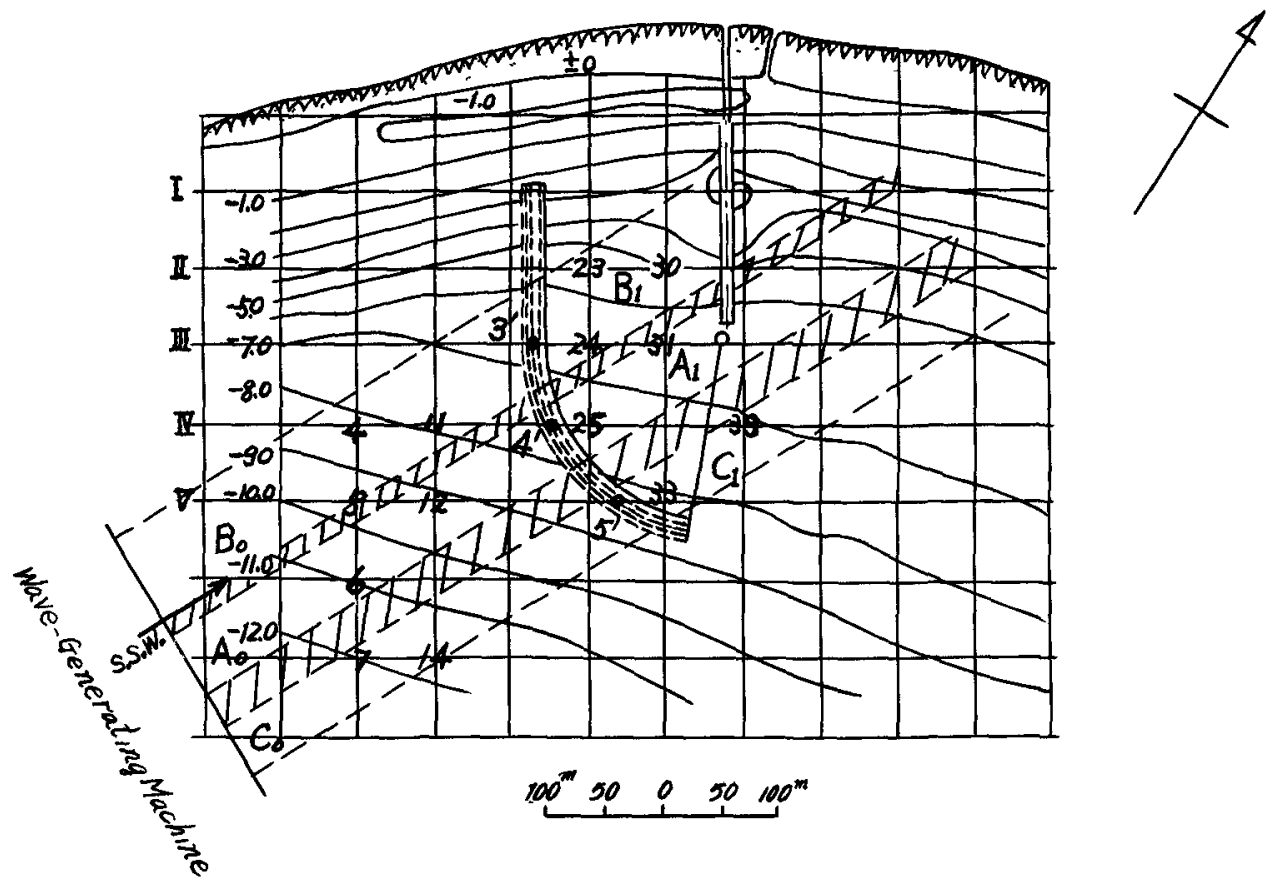

Point $3^{\prime}$ is selected at the intersection of line III and the center line between the two walls.

Point $4^{\prime}$ is selected at the intersection of line IV and the center line between the two walls.

Point $5^{\prime}$ is selected at the intersection of line $\nabla$ and the center line between the two walls.

Fig. 4. Plan of the Ichinotani coastal area. 
The elevation of the crown of the two walls and the clearances between the lower edge of each wall and the sea bottom are changeable. The combinations of dimensions, $t, 1, d, d$, $t_{2}, l_{2}, d_{2}$, and 1 , shown in Fig. 1 , are so many, that the author took up a limited number of combinations, and pursued experimental researches by a three-dimensional pool. In general, incident waves generated in the two-dimensional wave tank have beautiful and regular shape by the time before they become to be interfered with the reflected ones and the resulting waves are very complicated and irregularly standing, owing to no escape of reflecting ones. On the other hand, in the three-dimensional pool the reflecting waves are able to be restricted and also to be turned away by puting the opposite shore to be very gentle and wave-absorptive or to have a suitable reflecting plane alignment.

The model of curtain wall breakwater is consist of single curtain walls and supports. The model support is made of steel bars having $9 \mathrm{~mm}$ in diameter and $340 \mathrm{~mm}$ in length, we1ded to a base steel plate ( $6 \mathrm{~mm}$ thick and $200 \mathrm{~mm}$ wide) at 50 $\mathrm{mm}$ intervals. The model wall is thin wooden or lucite plate ( $10 \mathrm{~mm}$ or $5 \mathrm{~mm}$ thick) of micellaneous width. The latter is set up the former at a fixed position according to the still water level. The model double curtain wall breakwater is able to be easily constructed by placing two sets of the said model wall parallel to each other at a certain interval.

The wave generating machine is a plunger type and driven by 7.5 HP motor with a gear box and placed at a position shown in Fig. 4 in order to generate the said model wave propagating from $S S W$ to $N E$ direction.

During the experiments performed by the author, the following double wall conditions were taken as shown in Table 1 , where the model incldent wave of period $1.0 \mathrm{sec}$ and of length $130 \mathrm{~cm}$, was chosen.

Table 1 Double curtain wall conditions used in the Case $I$

\begin{tabular}{|c|c|c|c|}
\hline & & $t,(\mathrm{~cm})$ & $1(\mathrm{~cm})$ \\
\hline A & $\begin{array}{l}l_{1}=18.0 \mathrm{~cm} \\
l_{2}=18.0 \\
t_{2}=3.0\end{array}$ & $1.0 \quad 0.5,0$ & $15,20,30,40,50$ \\
\hline $\mathbf{B}$ & $\begin{array}{l}l_{1}=8.5 \\
l_{2}=18.0 \\
t_{2}=3.0\end{array}$ & $1.00 .5,0$ & Ditto \\
\hline C & $\begin{array}{l}l_{1}=8.5 \\
l_{2}=15.0 \\
t_{2}=3.0\end{array}$ & $\begin{aligned} 1.0, & 0.5,0 \\
-1.0, & -2.0\end{aligned}$ & Ditto \\
\hline
\end{tabular}


The alignment of the double curtain wall breakwater has a curved portion in order to minimize the length of the parallel portion of the fore wall to the crest line of incoming incident waves. Model wave height was measured at the intersection points of section lines covered the sea area shown in Fig. 4. Wave generator was adjusted so as to generate the desired model incident wave, before the installation of the double curtain wall breakwater, at the water area deeper than - $7.0 \mathrm{~m}$, and then wave height measurement was made at entire water area. After the model breakwater was set up, the same measurement were repeated.

The hit pattern of incident waves against the breakwater differs from portion to portion, the author divided the whole wall arrangement into three main sections, and also classified the water area into three main belts, namely, $A, A$; $B, B$; and $C, C$. Here, suffix o indicates the of fshore basin, and suffix $i$ indicates the inner protected basin. The interfered wave height at each belt of the offshore basin is obtained by averaging the measured wave heights, and at the same time the decreased wave height at each belt of the inner basin is got by the same method. The infiltrated and damed wave at the inner basin was hardly affected by the reflected wave from the shore in the model basin.

The most interesting phenomena which were seen in these experiments are as follows: (1) Wave pattern at the offshore basin varies according as the degree of wave dissipation by the said breakwater, in other words, as the degree of undulating water surface between the fore and the rear walls, and the wave height transmission coefficient and the ratio of the interfered wave height to the incident one at offshore basin are shown in Fig. 5 -Fig. 9. (2) The amplitude of undulating water surface at the limited narrow basin varies from place to place and also considerably varies according as the wall characteristics, and also as water level. Generally speaking, the stronger the incoming water over the fore wall crown is, the more violent the undulation within the limited basin becomes. (3) Undulation caused by the disturbing action of the overrun water or by the transmitted wave energy through the lower opening beneath the front wall within the narrow limited basin shows comparatively different pattern at each zone $A, B, C$. At zone $A$ or at point $4^{\prime}$ in Fig.4, the undulation shows an standing-wave-alike pattern. At zone $B$ or at point $3^{\prime}$ and at zone $C$ or at point $5^{\prime}$, the wave-crest generated by the said disturbing action propagates towards the each of the breakwater ends, at the same celerity as that of the running wave crest along the outer surface of the fore wall, and also the water particles move towards the breakwater ends, describing spirals.

As regards the wave dissipation effect of this type breakwater, the following important results are to be of great importance: (1) The efficiency of wave dissipation is higher in the case where intrusion of water mass into the limited basin between walls over the fore wall crown is easily permitted, than in the case where no such intrusion is allowed. 
As far as the elevation of the fore wall crown is concerned, if the dimensions of walls are fixed, a most suitable level difference above the selected still water level should be taken in order to determine it. (2) In order to heighten the wave dissipation efficiency at a possibly low cost; firstly, the distance 1 between two walls should be $0.2 \lambda-0.25 \lambda$, secondly, the crown elevation of the front wall should be lower

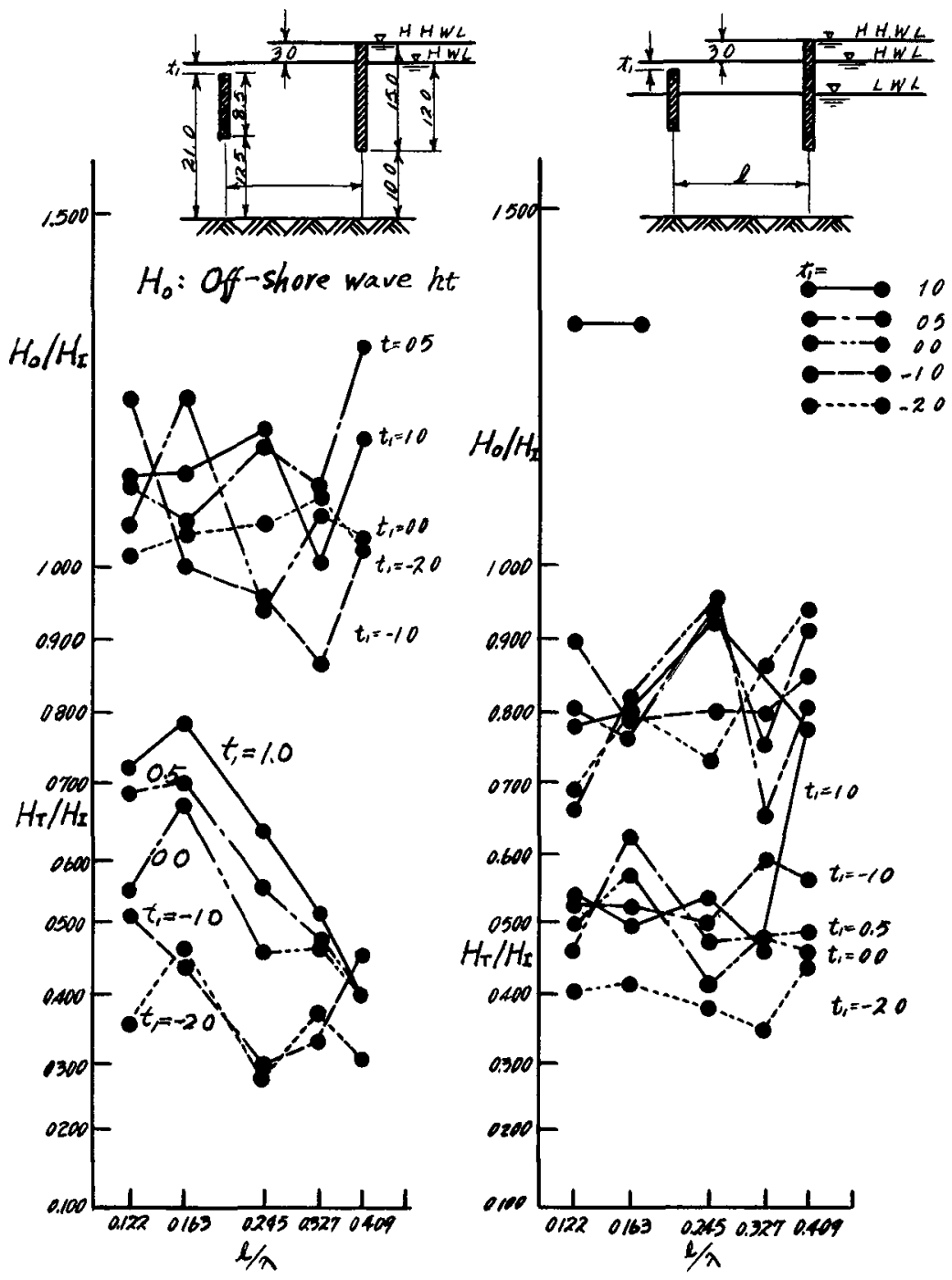

Fig. 5. Examples of wave-dissipation efficiency. 


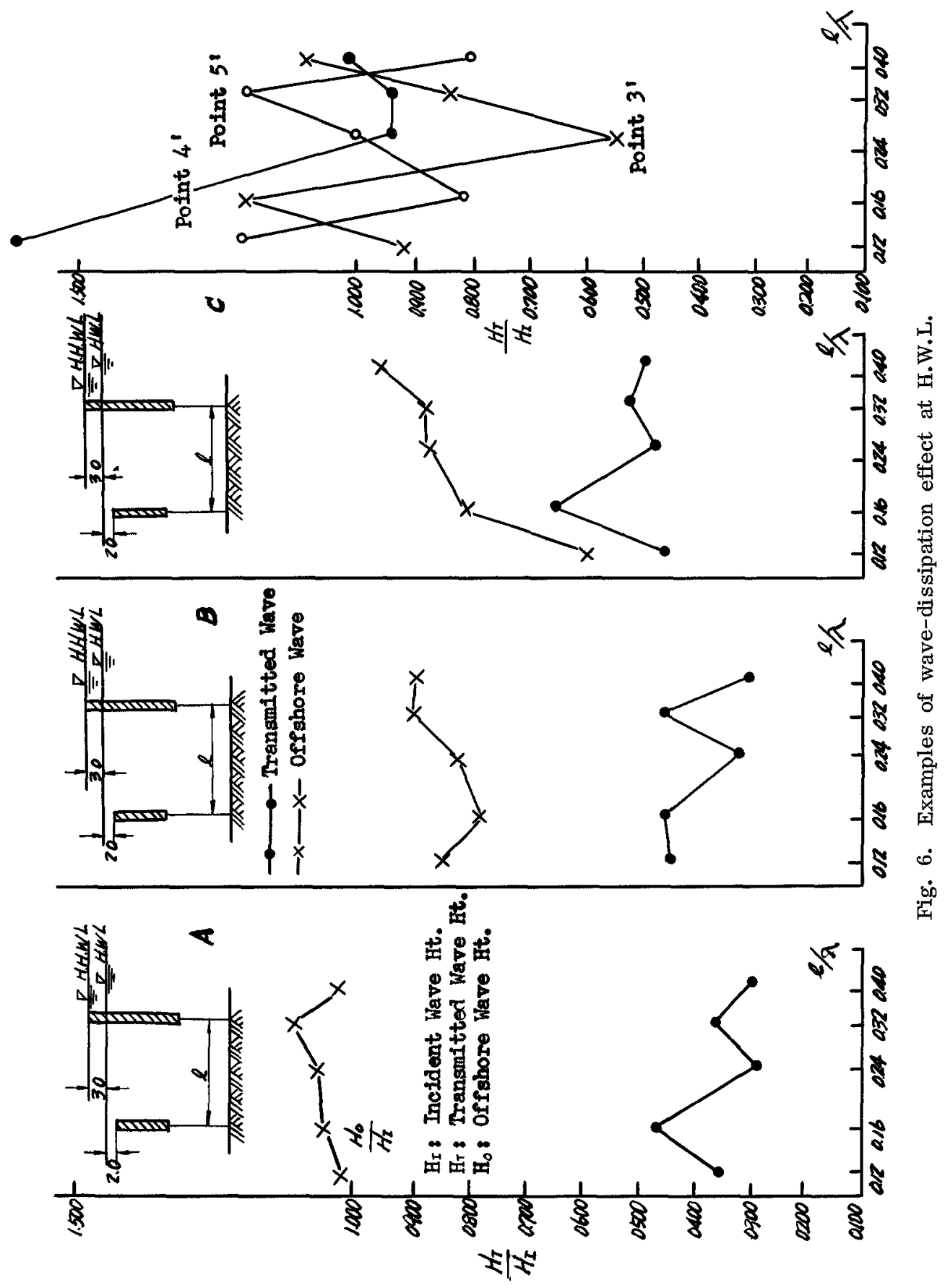



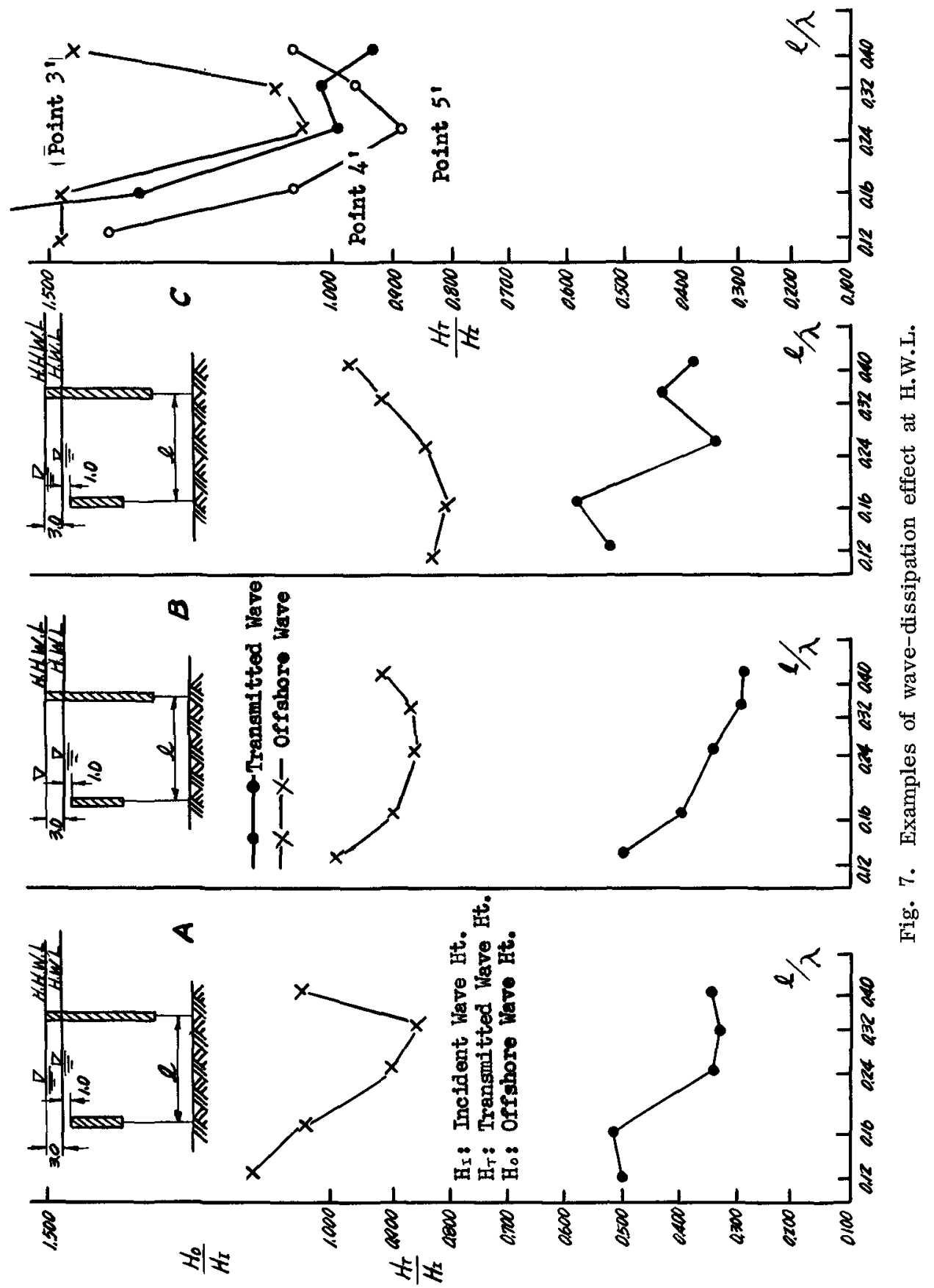

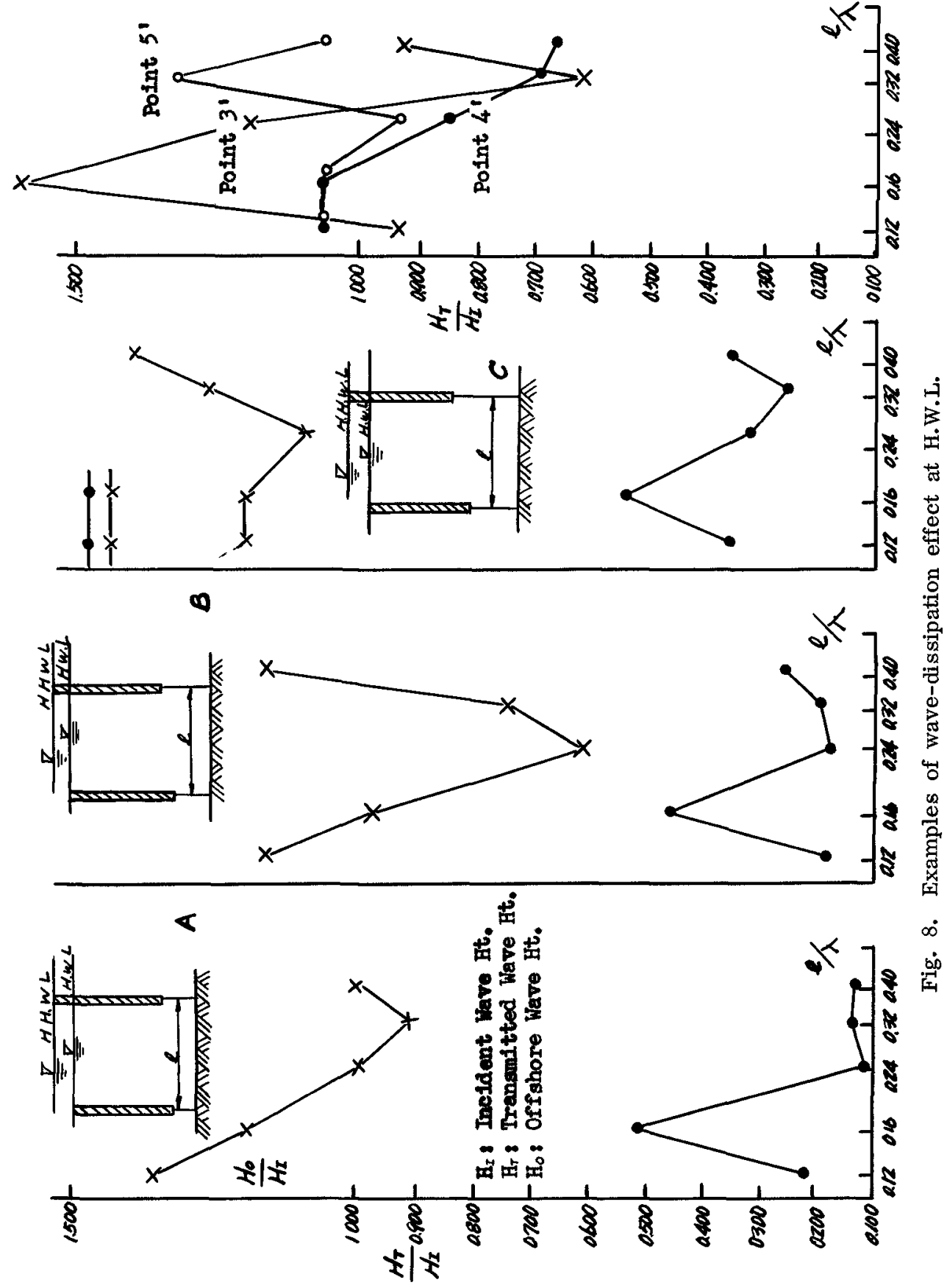

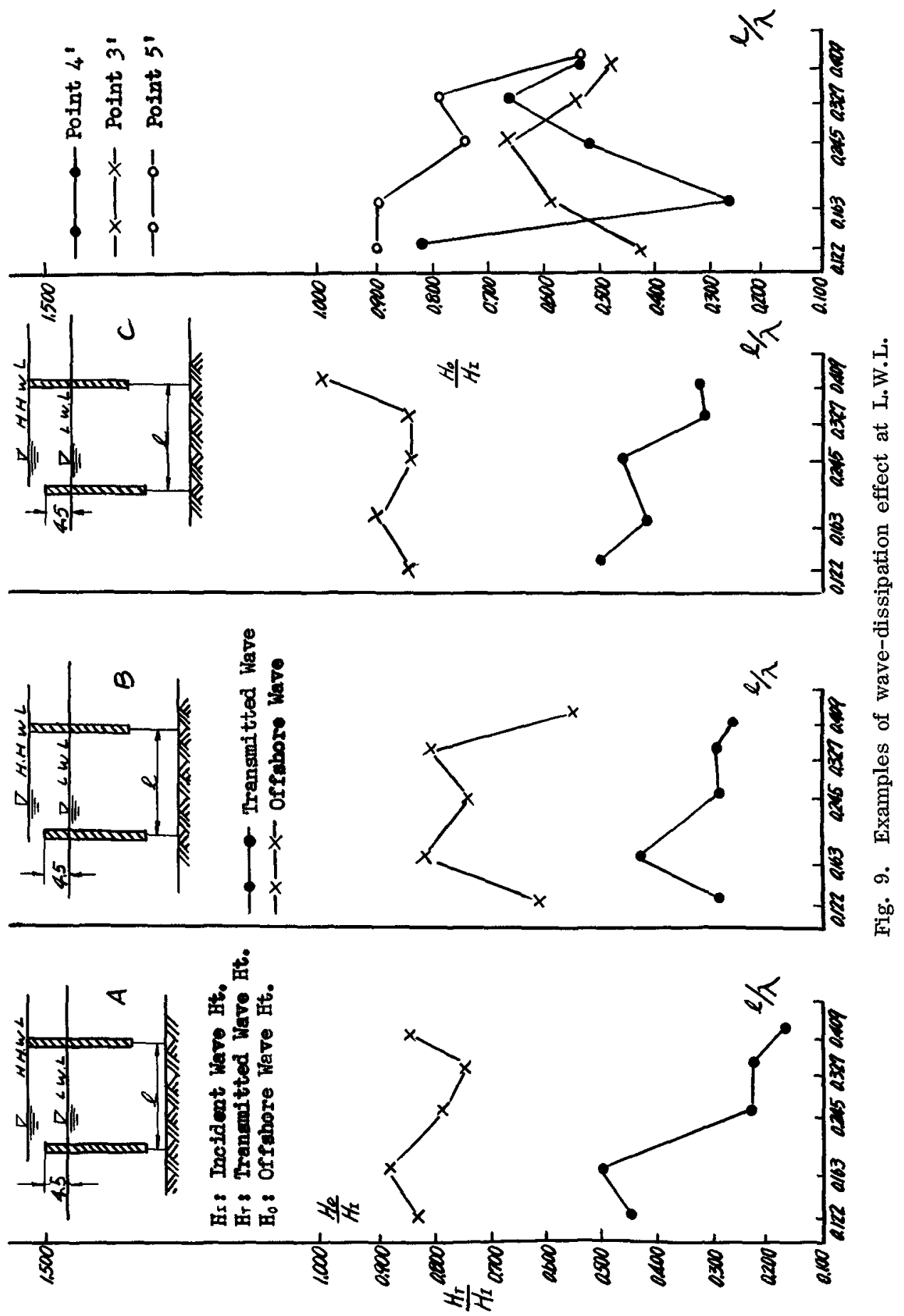
than the still water level to a certain extent, and thirdly, the crown elevation of the rear wall should be sufficiently high enough to permit no getting-over of disturbed water basin between two walls. (3) As regards the lower openings between the lower end of each wall and the sea bed, ( $d_{1}$ and $d_{2}$ in Fig. 1), the narrower they are the higher the dissipation efficiency becomes, but, the construction cost becomes very expensive.

\section{(2) Case 2}

The model was constructed in the same pool as stated in the Case 1 , in the scale of 1 to 70 , and the model sea bed is flat and horizontal at the construction site of breakwater, and the water depth below L. W. L. is $7.5 \mathrm{~m}$, and furthermore, the extraordinary high tidal level in the case of typhoon's visit above $L$. W. $L$. is chozen as $+3.0 \mathrm{~m}$. The characteristics of the design wave are the same as previously stated. In this case, a specially devised reflecting wall is installed at the end of the pool in order to avoid the interference of the reflecting wave with the transmitted wave at the protected basin, by diverting the reflecting wave into other basins.

In the experiments, the following double wall conditions were taken as shown in Table 2 .

Table 2 Double Curtain Wall Conditions used in the Case 2

\begin{tabular}{|c|c|c|c|c|}
\hline$t_{1} \quad(\mathrm{~cm})$ & $1,(\mathrm{~cm})$ & $t_{2}(\mathrm{~cm})$ & $1_{2}(\mathrm{~cm})$ & $1(\mathrm{~cm})$ \\
\hline $\begin{array}{l}1.0 \\
0.5\end{array}$ & $\begin{array}{l}4.0 \\
4.5\end{array}$ & 6.0 & 4.0 & \multirow{2}{*}{$\begin{array}{c}10.0,12.5, \\
15.0,17.5, \\
20.0,22.5, \\
25.0,27.5, \\
30.0\end{array}$} \\
\hline \multirow[t]{2}{*}{$\begin{array}{r}0.0 \\
-0.5 \\
-1.0 \\
-1.5 \\
-2.0\end{array}$} & $\begin{array}{l}5.0 \\
5.5 \\
6.0 \\
6.5 \\
7.0\end{array}$ & 5.0 & 5.0 & \\
\hline & \multicolumn{4}{|c|}{$\begin{array}{c}t_{1}+l_{1}=5.0 \mathrm{~cm}, t_{2}+l_{2}=10.0 \mathrm{~cm} \\
\lambda=100 \mathrm{~cm}, H_{\max }=15 \mathrm{~cm}\end{array}$} \\
\hline
\end{tabular}

The incident wave height was obtained by averaging the first ten successive wave height omitting the first two, because the said waves are not interfered with reflecting ones. The transmitted wave height is also obtained in the same way as outlined above.

Using the notations of important quantities shown in Fig. 1 , the values of $\mathrm{H}_{T} / \mathrm{H}_{I}$ (Wave Height Transmission Coefficient) are obtained experimentally, by changing $1, l_{1}$, and $l_{2}$, under the fixed value of still water depth, $H_{\max }$, and of $z_{1}$ and $z_{2}$. 
Fig. 10 shows a few examples of the relation between $\mathrm{H}_{\uparrow} /$ $H_{I}$ and $1 / \lambda$. Fig. 11 - Fig. 14 show some other examples indicating the relation between $\mathrm{HT} / \mathrm{HI}$ and the combination of 1 , and $\mathbf{l}_{2}$.

From these experimental results obtained, the value of $\mathrm{H}_{\mathrm{T}} / \mathrm{H}_{\mathrm{I}}$ becomes the minimum for $1 / \lambda=0.25$, under all conditions picked up; and also, the same value becomes the least when $t_{l}=-0.25 H_{I}$, and $l_{l}=H_{I}$, in this case.

(a)

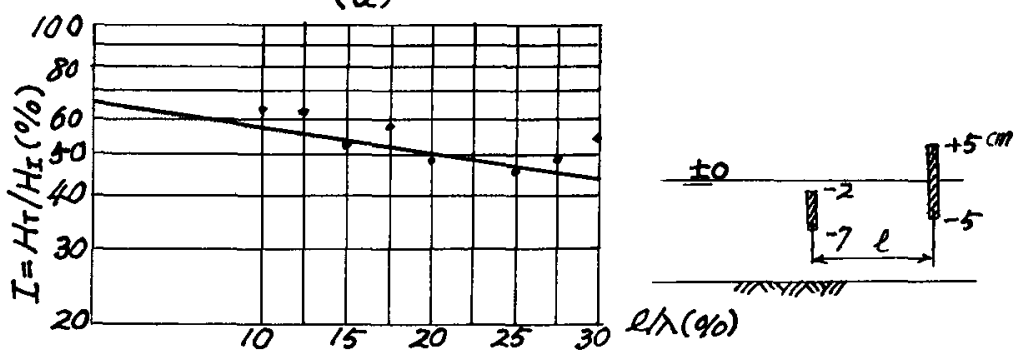

(b)

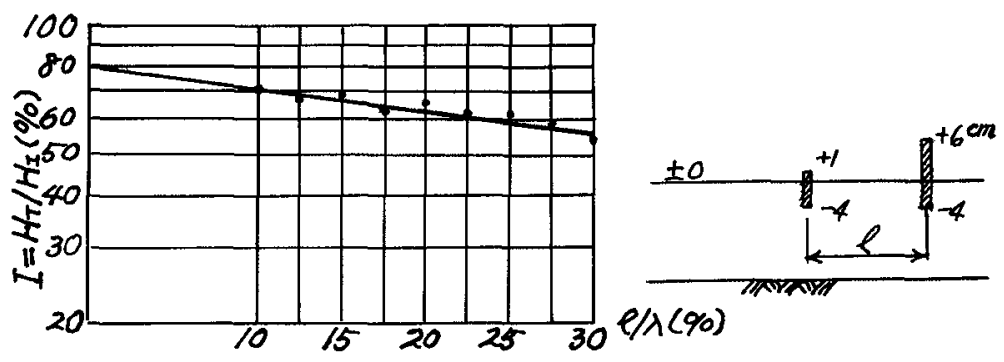

(c)

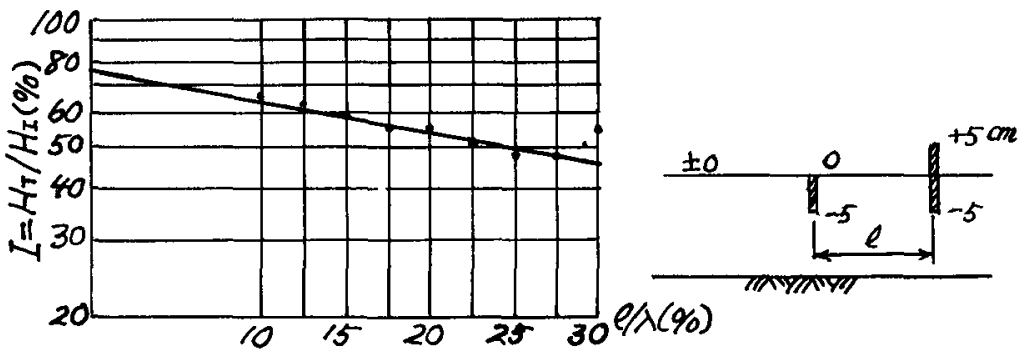

Fig. 10. Relation between $\mathrm{H}_{\mathrm{T}} / \mathrm{H}_{\mathrm{I}}$ and $1 / \lambda$. 


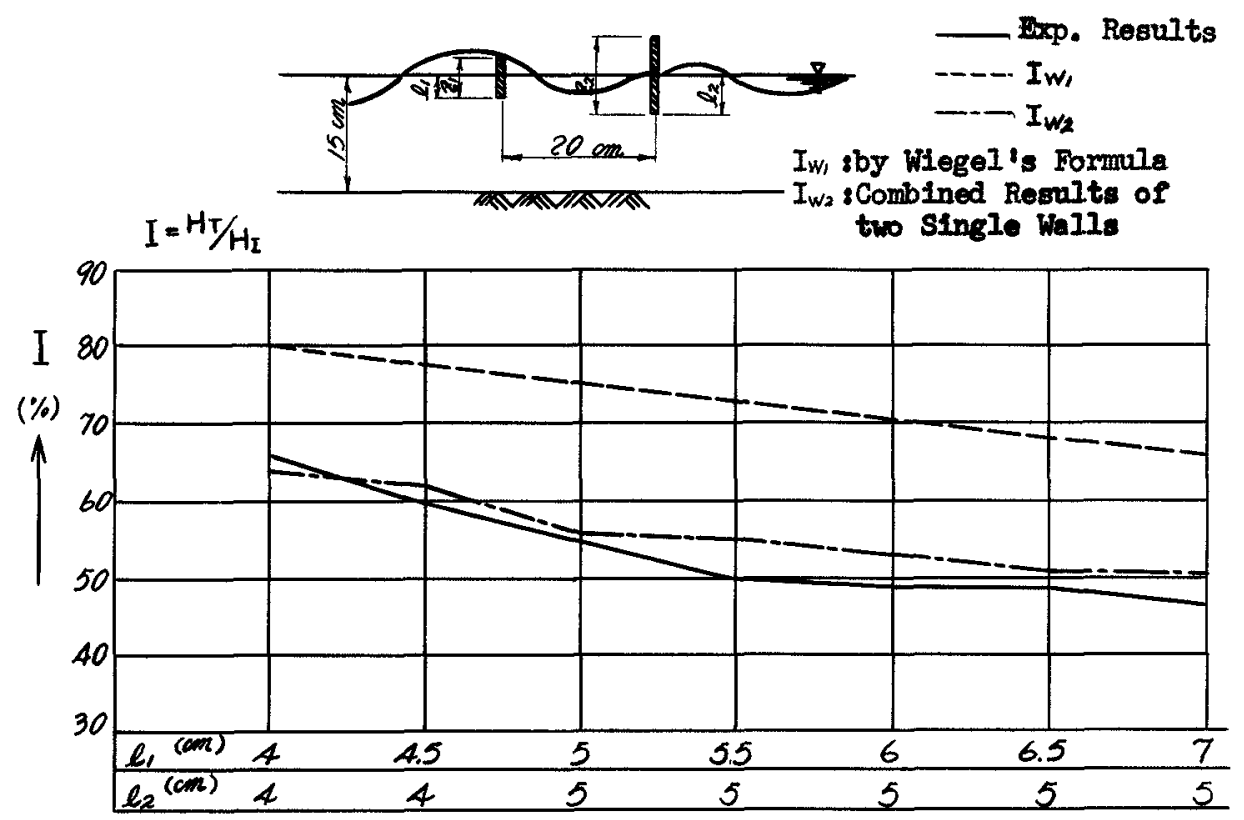

I Fig. 11. Values of I versus $1_{1}$ and $1_{2}$.

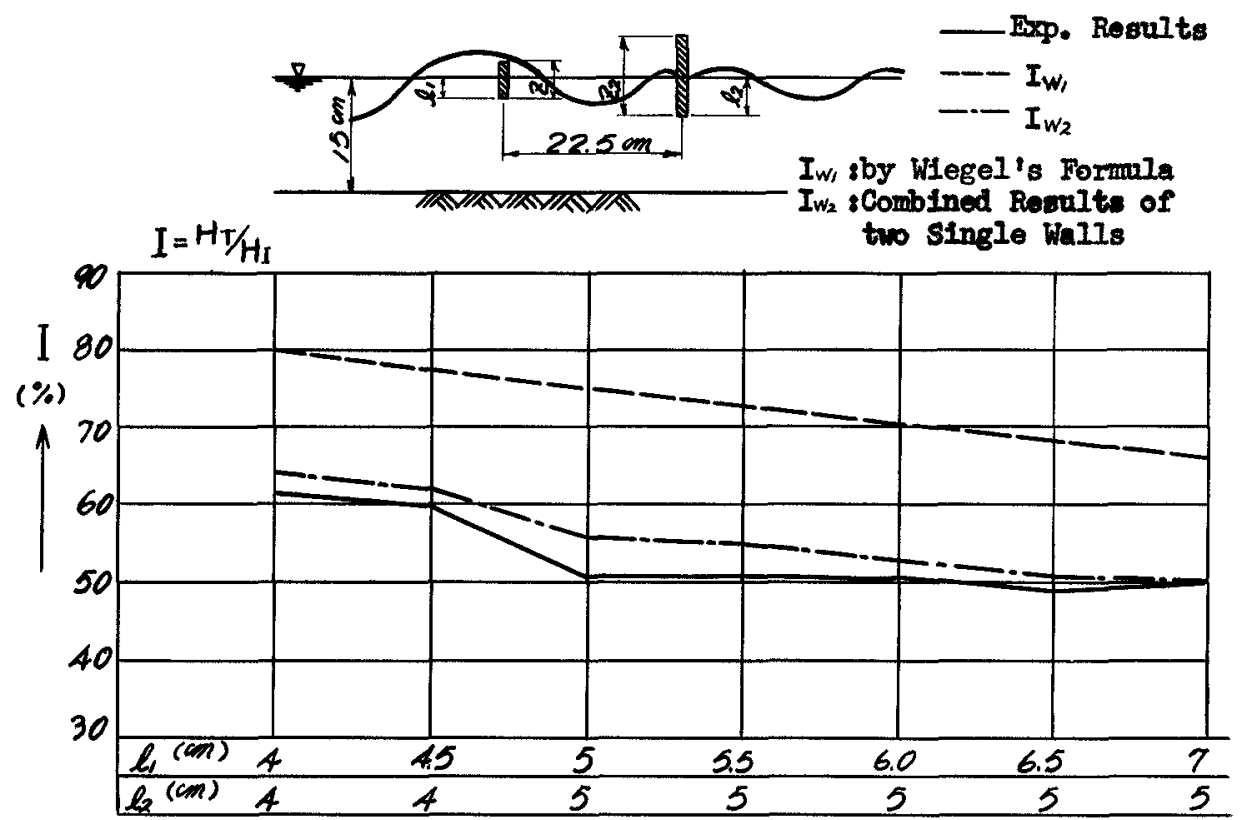

Fig. 12. Values of I versus $1_{1}$ and $1_{2}$. 


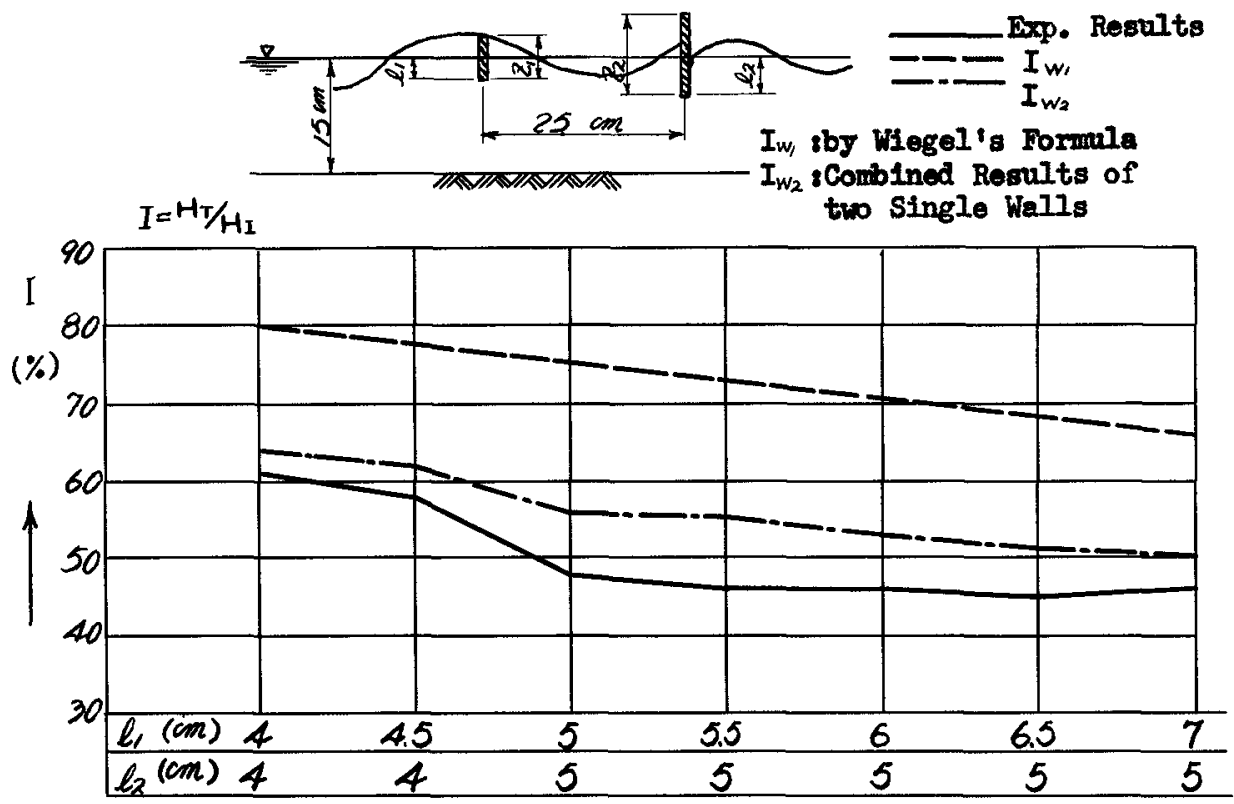

Fig. 13. Values of $I$ versus $1_{1}$ and $1_{2}$.

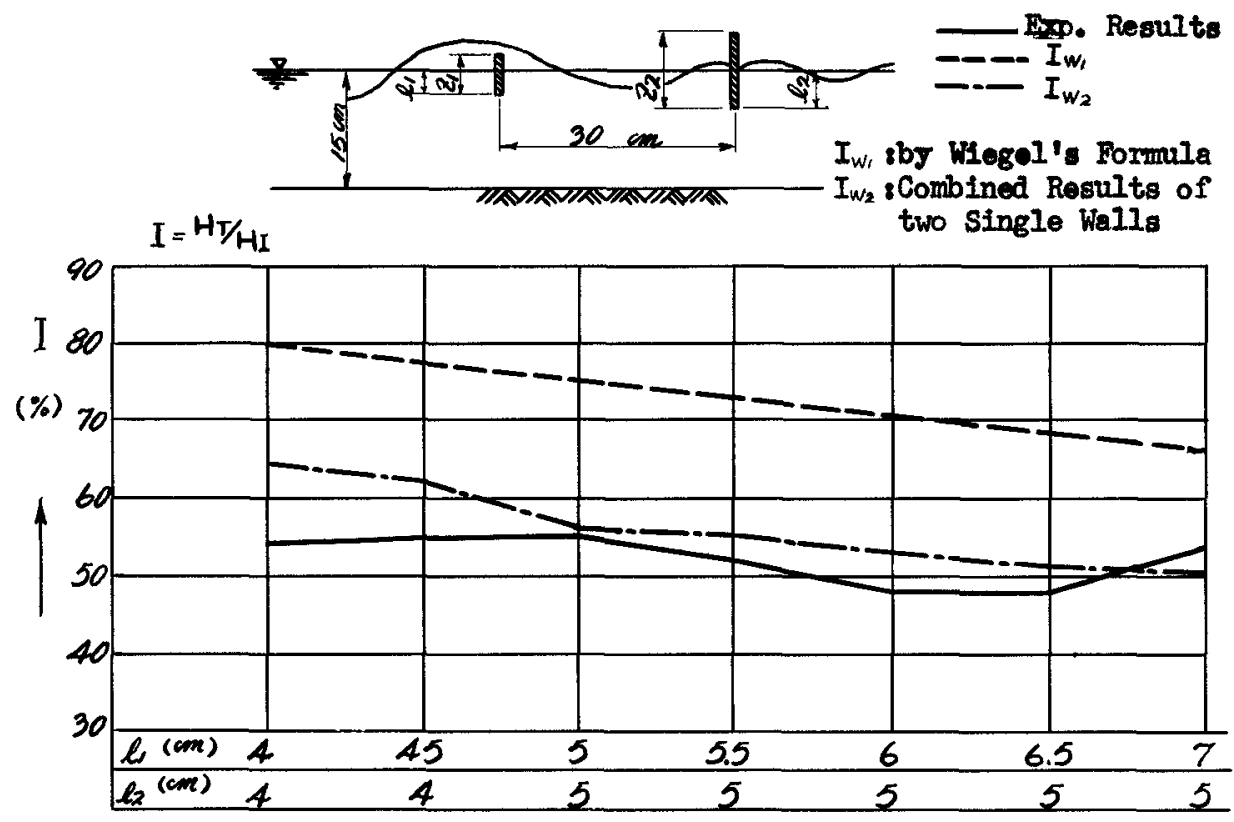

Fig. 14. Values of $I$ versus $1_{1}$ and $\mathbf{1}_{2}$. 


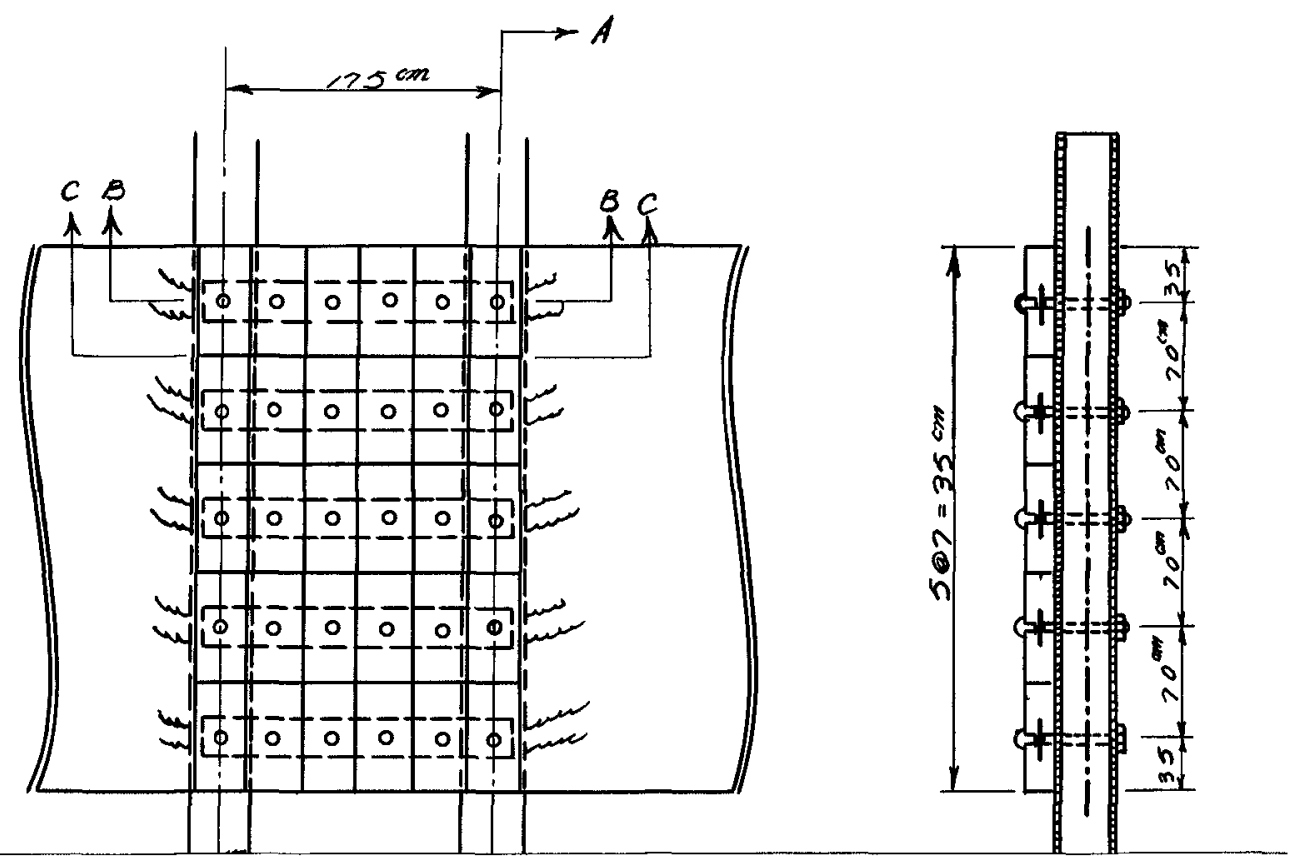

WAVE PRESSURE DISTRIBUTION EXERTED ON THE WALLS

In order to measure the wave pressure distribution acting on wall, the author cut down the fore and the rear wall boards attached at the center span of supporting props, and then replaced five vertically piled horizontal steel-casings covered with water-tight thin rubber film. The casings are fixed to the supporting props. One casing is composed of six pieces of hollow rectangular ring of $2 \mathrm{~mm}$ thick and is flexible. A spring-steel strip $(0.8 \times 2.4 \times 200 \mathrm{~mm})$ is held at the center of each casing and fixed to a support at one end and the other end of it is allowed to slide. Each casing has the same width as that of the wall. The wave-pressure measuring device used by the author is shown 1 Fig. 15 and Fig. 16 .

The pressure distribution was obtained by measring the strain caused on each of the spring-steel-strips placed horizontally with small clearances between the adjacent ones, by the dynamic action of water disturbances generated between the two walls.

Fig. 17 shows one of the experimental results obtained, pointing out the dynamic pressure distribution on the front surface of the rear wall, and also shows the wave pressure distribution on a vertical wall. computed by Sainflou's for- 


\section{CONCLUSION}

By this research the author clarified the effectiveness of the double curtain wall from the view point of wave dissipation, not only for the comparatively small wave but also for the large wind wave induced by heavy typhoon. The author wishes to recommend the following dimensions of the two walls for the design wave; $z_{1}=H_{I}, z_{2}=2 H_{I}, 1=0.25 \lambda, t_{1}=-0.25 H_{I}$, where $H_{I}$ is the design wave height and $\lambda$ is the design wave length. The author also wishes to obtain the supporting structure which is hydraulically most ecconomical, by making further research concerning wave-pressure-distribution on this type of breakwater.

\section{ACKNOWLEDGMENT}

The author wishes to express his sincere gratitude to the officials of the Reclamation Works Bureau of Kobe City office for their kind support and to Mr. M. Ikeda who is his Assistant and to Mr. M. Nakajima who was a graduate student of Kobe University for their energetic and sincere assistance in experimental works.

\section{REFERENCES}

1) R. L. Wiegel: Transmission of Wave Past a Rigid Vertical Thin Barrier, Proc. of the American Soc. of Civil Engineers, Waterways \& Harbor Div. W W 1, March, 1960.

2) F. Ursell: The Effect of a Vertical Barrier on Surface Waves in Deep Water, Proc. Cambridge Phil. Soc. Vol.43, Part 3, July, 1947 .

3) R. Morihira \& S. Anezaki : Researches on "Single Curtain Wall Breakwater and Its Characteristics", Lecture Papers of llth Annual Lecture Meeting of Coastal Engineering in JSCE, Nov., 1964. (in Japanese) 